\title{
Obesity is an Eating Disorder not a Disease
}

\section{Sarfraz Hussain1, Qaisar Raza ${ }^{2 *}$, Itrat Fatima1, Syeda Mahvish Zahra' and Farhat Rashid ${ }^{1}$}

${ }^{1}$ Institute of Food Science and Nutrition, University of Sargodha, Pakistan

${ }^{2}$ Department of Health Sciences, Vrije Universiteit Amsterdam, De Boelelaan 1085, Kamer O-534, 1081 HV Amsterdam, The Netherlands

\begin{abstract}
Blood group diet research is gaining popularity among scientists and they are exploring new reasons to preferences of diet in four blood group type individuals. The concept of balanced diet and nutrition seems not to be working properly because diseases like obesity, diabetes, CVD, and cancer are causing millions of deaths each year in the world. Many scientists still did not pay any attention to the strong correlation between blood group diet and diseases except few in the world. There are strong evidences that these four blood group individuals have different taste buds which are the bases for selection of foods which ultimately become nutrition of that individual. A very nutritious food if not selected by a person having a particular blood group will provide no any nutrition to that particular individual. Blood group "A" has bland, "B" has sweet, "O" has saltish, and "AB" has bitter and astringent taste buds. Distribution of blood group types in different regions of the world indicates that there are strong variations in blood group diet because all four blood group types have four different types of tissues (A- nervous, B-epithelial, O-muscular and AB-connective). Macro and micronutrients are also specific to these blood group types (A-Zinc \& Magnesium, B-Iron, O-lodine and AB need additional calcium). Pakistan has blood groups population as "B" $36 \%$, "O" $33 \%$, "A" $21 \%$, and "AB" $9 \%$. USDA diet pyramids were designed to guide about the diet of Human beings living in different regions of the world. But these diet pyramids are no more valid because of the reason that they are nutritionally and biochemically unsound, but still in many countries these pyramids are being used for the assessment of diet without any positive effects. A diet pyramid based on blood groups is designed to guide about the diet of individuals based on blood groups. Diet charts formulated for four blood group types are based on scientific correlation to prevent diseases and remain healthy.
\end{abstract}

\section{Keywords: Obesity; Blood groups; Diet; Diseases; Nutrients}

\section{Introduction}

Obesity is not a disease but it is an eating disorder. Before the author came to know about the work [1-5], the author knew that climatic conditions have a strong correlation with the availability of seasonal fruits and vegetables and the diseases which spread out in a specific season. All foods coming in a season are real source to combat seasonal variations a gift by God. Most of these diseases are related to season and eating not according to blood groups. Deficiency of certain major nutrients, minerals and vitamins also result in deficiency diseases. Peter said that there is a protein in blood of each individual known as Lection but these proteins have different functions in each blood group to combine with certain types of sugars in foods we eat and allow the blood to agglutinate or not. When someone says that I like this food or I dislike that food means something very important. Most of the World's scientists conducting human studies are not bothering about a strong biomarker that is blood group. While to be on a safe side they should know about distribution of four blood groups in different regions of the world and think unbiased that what variable effects of these four different blood groups may pose different error in their research. Obesity is related to blood group "AB" having connective tissues as major tissues demanding high calcium and hot foods [6]. Sensory scientists say that bitter and astringent taste is liked by blood group "AB" people. Also medicines being sold in the market to reduce weight contain bitter plant extracts, which provide energy to the body to keep it warm and support the function of spleen. If function of spleen is perfect, the body will not be obese. One such food is bitter gourd. As connective tissues of blood group "AB" are coldest in rhea body will not support movement of and digestion of food until and unless hot foods are not taken. Ispagola husk is also producing very deleterious effects on patients feeling constipation. It has strong cool and wet (humidifying) effect on body. If taken continuously by three blood groups ( $\mathrm{A}, \mathrm{AB}$ and $\mathrm{O}$ ) will produce paralyses in these three blood group individuals. This is very interesting to note that a women having "AB" blood group did not become pregnant during 15 years of marital life in spite of many genie courses having husband with blood group "A" as this blood group is having lower acid production in both male and female population and lower FSH level [1].

This blood group is having nervous tissues as major tissues demanding nerves supporting foods (almond, walnuts, pine nuts, etc. as source of Zinc and Magnesium to activate 300 enzymes in their stomach) became pregnant when diet counseling according to blood groups was advised to husband and wife. The connective tissues (mainly bones) are the most cold parts in the body and special low sperm count in male and cold shrunken ovaries to become pregnant (sperm die in this type of ovary) and unable to deliver a healthy baby. According to the data available on net, most of the American population have blood group "O" who need red meat, table salt, MSG, Soy sauce, onion, Ginger, garlic and tomatoes and not mostly bakery food items and not dairy items except cow's milk, cow's clarified butter. Obesity in "AB" blood groups is most prevalent in cold climates (mostly European countries). This eating disorder becomes more prominent in coldest season in winter from November $25^{\text {th }}$ to December $11^{\text {th }}$ which shows

*Corresponding author: Raza Q, Department of Health Sciences, Vrije Universiteit Amsterdam, De Boelelaan 1085, Kamer O-534, 1081 HV Amsterdam, The Netherlands, Tel:+31 2059 89898; E-mail: In.uv@azar.q

Received September 09, 2017; Accepted September 19, 2017; Published November 01, 2017

Citation: Hussain S, Raza Q, Fatima I, Zahra SM, Rashid F (2017) Obesity is an Eating Disorder not a Disease. J Blood Lymph 7: 181. doi: 10.4172/21657831.1000181

Copyright: (c) 2017 Hussain S, et al. This is an open-access article distributed under the terms of the Creative Commons Attribution License, which permits unrestricted use, distribution, and reproduction in any medium, provided the original author and source are credited. 
Citation: Hussain S, Raza Q, Fatima I, Zahra SM, Rashid F (2017) Obesity is an Eating Disorder not a Disease. J Blood Lymph 7: 181. doi: 10.4172/2165-7831.1000181

Page 2 of 4

that this eating disorder is very common in cold countries. So it is better for these people to live in warm climatic regions. Meian et al. [3] reported that people having blood group " $A B$ " are most vulnerable to heart attack and "O" is most resistant (research was conducted at Harvard School of Public Health and published in American Journal of Heart association) the study was conducted on 90,000 patients and was followed up for twenty years. We should avoid mirages and climatic conditions to formulate blood group " $\mathrm{AB}$ " to avoid heart attacks due to cold body conditions. Now we have an idea that who should marry with which blood group individuals [6,7]. Similarly "A" male have more female babies in cold regions. There are some specific diseases which have close correlation with climatic conditions to give birth to female babies. The concept of balance diet and nutrition need revision in the light of four blood group individuals on the basis of their active relevant tissues and their different energy and specific nutrient requirements as "O" has muscular, "A" has nervous, "B" has epithelial and "AB" has connective tissues [7]. Similarly these four blood groups have different taste buds as "O has most liking of saltish taste (helpful for the highest production of $\mathrm{HCl}$ in the stomach - also need Iodine to support energy production in the body due to heavy and quick loss, this blood group mostly prevails in hot regions of the world near equator). The most prevalent blood groups in the world are 62\% "O", 21\% "A", 16\% "B" and the least is $1 \%$ "AB" (Figures 1-4). A new definition of balanced diet and nutrition may be as "it is an in built capacity of mind of a person having a particular blood group which is based on a specific taste bud (bland taste " $A$ ", sweet taste " $B$ ", bitter \& astringent "AB" and Saltish "O") for the selection of diet which ultimately becomes balanced diet and provide nutrition to that particular blood group individual and this capacity is independent of age, sex and sanity. Carbonated beverages are one of the main reasons of obesity and not suitable for blood group "AB". Especially phosphoric acid will deplete calcium from bones of blood group "AB". If we go through the literature and read about the function of calcium in the body will tell that it is essential for the integrity of blood vessels to allow better flow of blood. Many countries are very much conscious about obesity of their population and want to reduce it. In University college London a nutritional survey was conducted which resulted that one out of 10 young children between the ages of 2 to 10 , and young people aged 11 to 18 will be obese for the years 1995 to 2007 . As a thumb rule we should eat diet having opposite characteristics to the season. The following season circle tells what diet to take according to changing climates and also eat foods according to blood groups [4]. Reviewing following diseases which are said to be prevalent in blood group " $\mathrm{AB}$ " are having deleterious consequences on individuals having this particular blood group though this group is

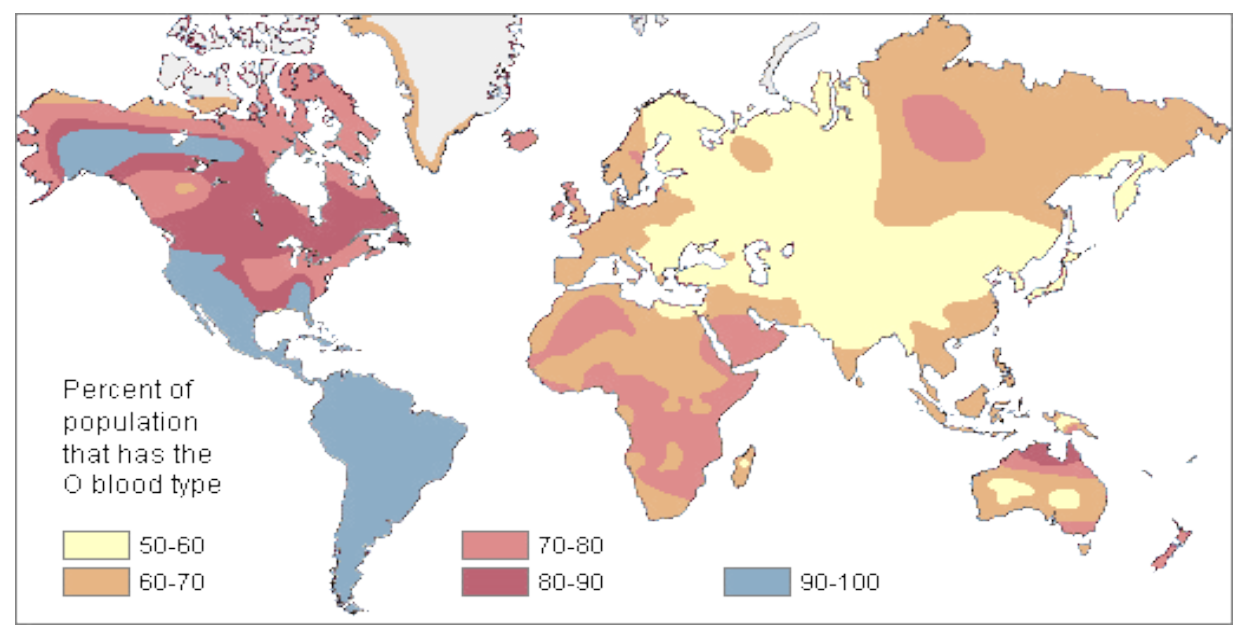

Figure 1: Most prevalent (62\%) blood group "O" in the world.

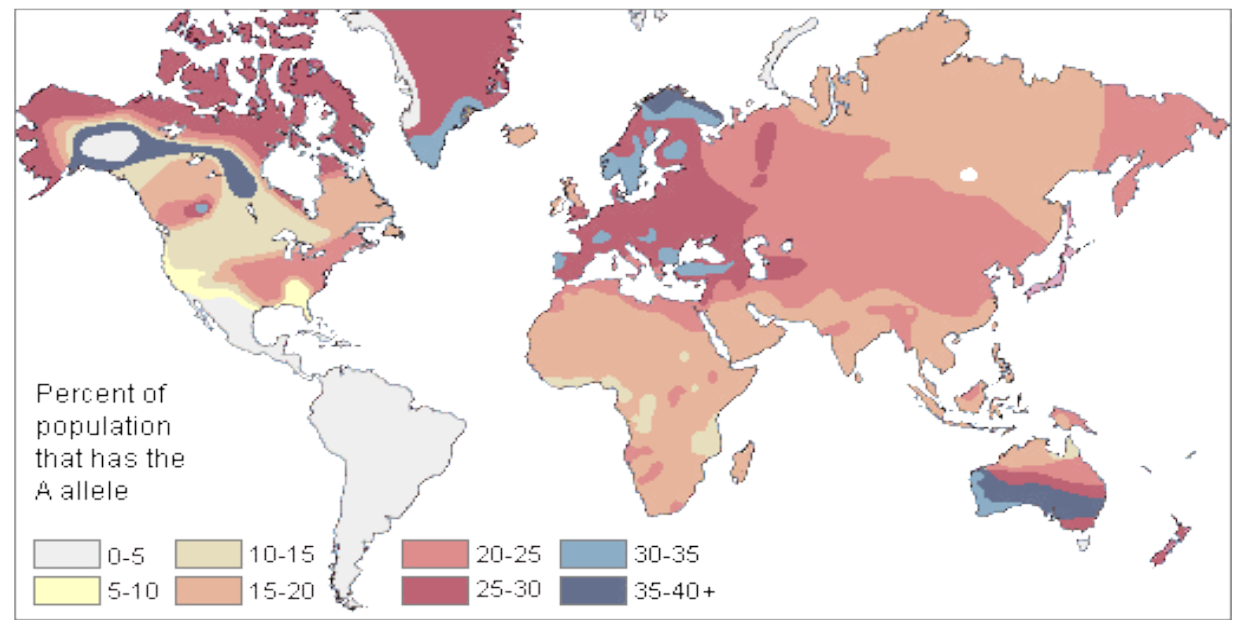

Figure 2: Second most prevalent (21\%) blood group "A" in the world. 


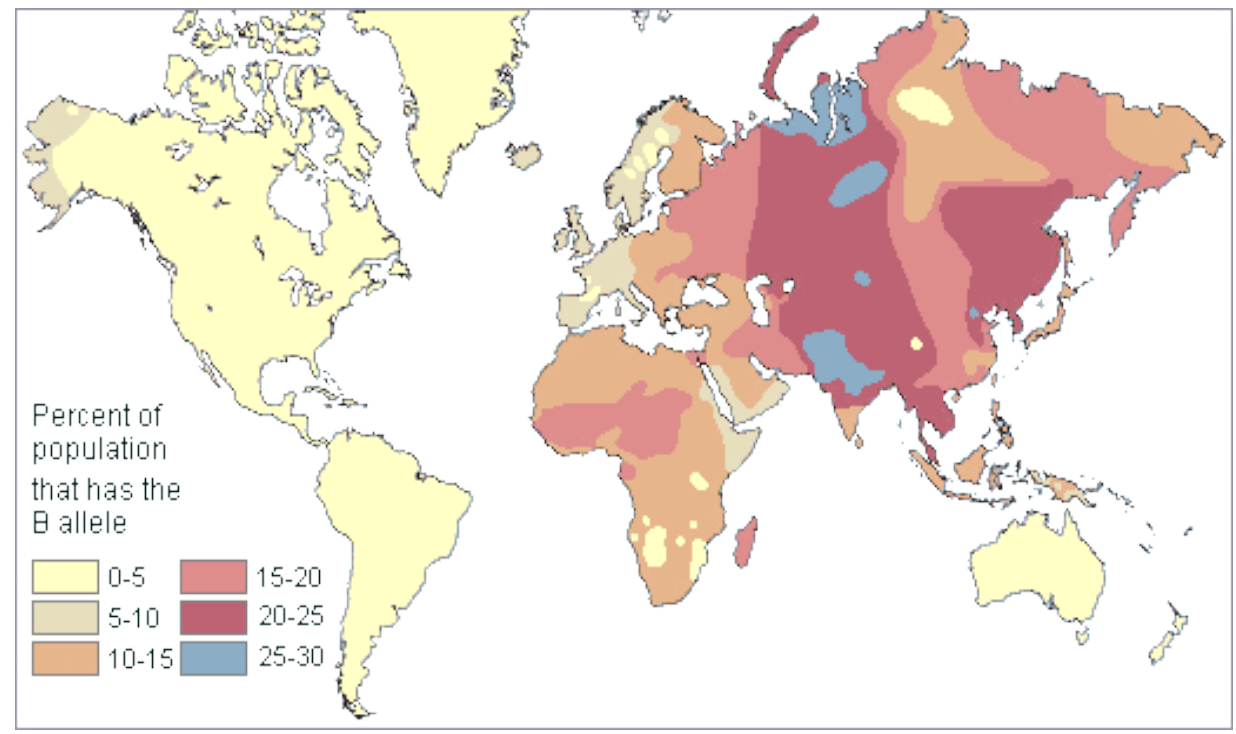

Figure 3: Second most prevalent (16\%) blood group "B" in the world.

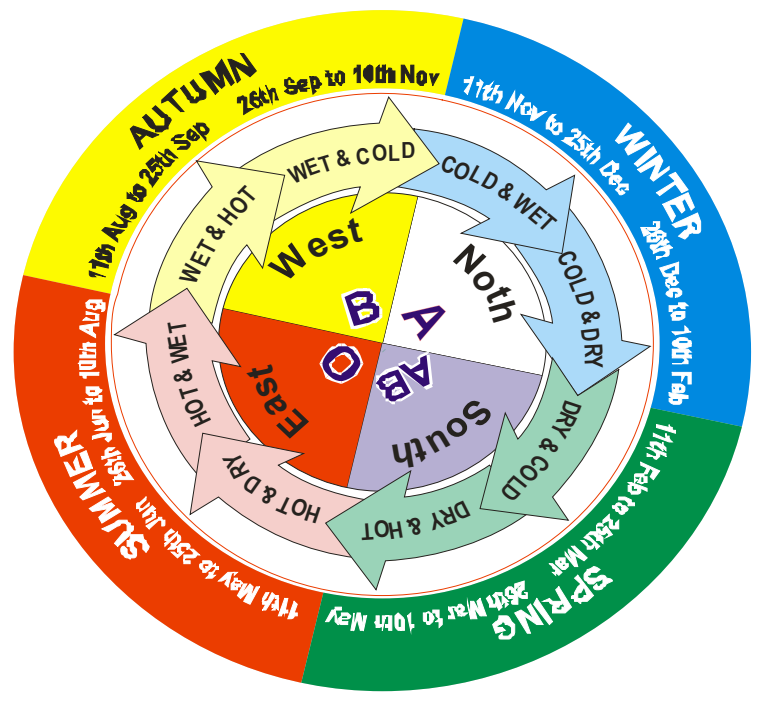

Figure 4: Blood groups and changing season circle. Blue color shows phlegmatic "A" green color shows black bile "AB" group, Red color shows blood "O" group and yellow color shows yellow bile "B" blood group.

very minor i.e. only $1 \%$ in the world population. All these diseases have one very common reason is cold climate and need to be very specific to diet as hot and dry in cold and wet season and similarly hot and wet in cold and dry season in different regions.

\section{Diseases of blood group “AB”}

Apoplexy, asthma due to black bile, atherosclerosis, celebrities, cold cough, cramping of muscles, dull minded, heartbeat abnormal, nightmare, rheumatism, scrofula, senselessness of hands, feet \& organs, shriveling of body, small genital male organ, weakness of brain due to low blood circulation [5].

\section{After effects of Deposition of Excessive Black Bile in the Body}

Amnesia, backed baldness/loss of hair, black jaundice, blood thickness, burbs due to indigestion, cancerous clotting in body, coldness of ovary, constipation, enlargement of liver, enlargement of spleen, facial paralysis, body paralysis, deafness, eczema, fibroid, fistulainano, gas in stomach, habitual abortion/ inability to become pregnant, heart attack, hepatitis - $\mathrm{C}$, cholesterol, intestines remained filled with feases, lazyness, leukemia, low male sexual power, Malarial fever, meningitis/sarsam, obesity, oligomenorrhea, pain at the back of ear/kanpati ka dard, pneumonia, psoriasis/Chambal, qolic, quarten fever, shrinkage of liver, slakeness, snail and thread worms in intestine, spleenitis (target organ in blood group "AB"), stone in kidney and bladder, sterility, weak or loose muscles [5]. Afridi and Khan [6] studied the causes of obesity in Pakistan and due to the reason that blood group ' $\mathrm{B}$ " is most prevalent in the country but in spite of highest $\mathrm{BMI}$ it does not have much fat in the body because this blood group has natural tendency to retain water in the body and the target organ is liver which needs excessive water to cool down the liver and drink glucose. It is wonder of nature that this blood group is not prevalent in the world as much it is present in sub-continent, todays Pakistan and India. The anthropometric data was collected through analysis with anthropometric machine. It is suggested that cut off values must be fixed according to the prevalence of blood groups in the world. All four blood groups living in a region will reflect true BMI values estimated on the basis of climatic conditions and prevalence of these blood groups in that region. Most prevalent and least prevalent blood groups are also affected by not only climate but diet available also. Detail studies on specific diet according to its availability and according to climatic conditions can be explored worldwide through research.

\section{References}

1. Anonymous (2008) Annual Health Survey of London, UK

2. Edward Nejat (Undated) Study carried out at Albert Einstein college of Medicine, New York.

3. Meian He, Brian W, Kathy R, JoAnn EM, Eric R (2012) ABO blood group and risk of coronary heart disease in two prospective cohort studies. Atherosclerosis, thrombosis and vascular biology. Art Thromb And Vasc Bi 32: 2314-2320.

4. Peter JDA, Catherine W (2000) Live Right 4 Your Type - 4 blood types 4-programmes for a healthy life. Distributors Stacktheme Ltd, 59 Bridge Street, Dollar, FK 147DQ, Scotland, UK.

5. Faiz MF (2002) Quliat-e-Tib-e-Islami (Keys to Islamic way of Healing) (In Urdu) 
Citation: Hussain S, Raza Q, Fatima I, Zahra SM, Rashid F (2017) Obesity is an Eating Disorder not a Disease. J Blood Lymph 7: 181. doi: 10.4172/2165-7831.1000181

Page 4 of 4

Faiz UI Hikmat, Islamia College, 54-stop, Street No.1, Yasir Ghafar Town, Okara, Pakistan.

6. Afridi AK, Khan A (2004) Prevelance and etiology of obesity. An overview. Pak J Nutr 3: 14-25.
7. Babar SQM (2005) Tehqiqat-e-insani blood group-Ghiza-tib-aur homeo pathy (research on Human blood groups-diet-greek medicinal practices and homeopatiy) (In Urdu). Rahim centre, Press market, Amin pur bazar, Faisalabad, Pakistan, pp: 384. 